\title{
The changing seasonality of infant deaths in England and Wales 1912-78 and its relation to seasonal temperature
}

\author{
E. H. HARE \\ From the Maudsley Hospital, London \\ P. A. P. MORAN \\ From the Australian National University, Canberra
}

\author{
A. MACFARLANE \\ From the National Perinatal Epidemiology Unit, Radcliffe Infirmary, Oxford
}

SUMMARY Seasonal variation in the rates of stillbirth, and of deaths under the age of one year, were studied for England and Wales in order to examine (a) changes in the seasonal variation over the years and (b) the correlation between seasonal rates and seasonal temperatures. The quarterly rates of stillbirths were studied for the period 1928-78; and of deaths under the age of one year, in six different age groups, for the period 1912-78. A disappearance of seasonal variation in rates ('deseasonality') occurred for stillbirths in about 1950, and for neonatal deaths in about 1965 . For deaths at 1-2 months a trend towards deseasonality has been apparent since 1955, but there has been no such trend for deaths at 3-11 months of age. In the period before deseasonality, and for the first quarter of the year, there was a high negative correlation between the neonatal death rate and the mean temperature in England and Wales but this correlation fell as the seasonal variation in rates fell. The findings suggest that seasonal variation in the neonatal death rate was closely related to winter temperatures during the period 1921-60. For deaths at 1-11 months old, there has been and still is a relation between temperature and seasonal variation in rates, but the relation was less close than for the neonatal death rate.

\begin{abstract}
A number of British studies have shown a correlation between mortality from respiratory disease in young children and the temperature in the week, or in the two weeks, before death. ${ }^{1-3}$ But although it has long been observed that spells of cold weather are associated with an increase in the number of deaths during childhood, there appear to have been no formal reports of a correlation between seasonal death rates (from all causes) in infants and the corresponding seasonal temperature. Such a correlation might reasonably be expected whenever there is a marked seasonal variation in rates. Official statistics show that there was a marked seasonal variation in neonatal deaths during the interwar years which no longer occurs, and it seems likely that this change is an example of the phenomenon which Sakamoto-Momiyama` has called 'deseasonality'.
\end{abstract}

These considerations led us to make the present study, in which our aims were (a) to trace, for England and Wales, the changing pattern of seasonal variation in death rates for a series of age groups under one year covering as long a period as possible (which was the period 1911-78); (b) to examine correlations between seasonal death rates and mean seasonal temperature, and how such correlations might be affected by the phenomenon of deseasonality; and (c) to examine the correlation between death rate and the extent of seasonal variation.

\section{Method}

From the annual statistical reports of the Registrar General and the later reports of the Office of 
Population Censuses and Surveys, data on the quarterly numbers of deaths in England and Wales are available for each year since 1911 and for deaths at the following ages: less than one week, $1-4$ weeks, 1-2 months (that is, more than one completed month of age and not more than three completed months), 3-5 months, 6-8 months, and 9-11 months. Data on the quarterly numbers of live births have been made available only since 1921 , but for the years 1911-20 we were able to estimate the quarterly number of births from the number of deaths (as above) and the corresponding death rates. ${ }^{5}$ Quarterly numbers of stillbirths have been made available only from mid-1927.

Tables of the mean temperature at sea level in England and Wales, by month, were supplied to us by the Meteorological Office. This temperature is the mean of temperatures recorded at six or seven stations in each of the eight meteorological areas of England and Wales, adjusted as necessary for height above sea level. Measurement dates from 1876. For the years when mean quarterly temperatures were not given in the Registrar General's annual reports we calculated these as the average of the corresponding monthly means.

Death rates were calculated on the basis of cohort births. For a small age range, it will be a reasonable assumption that the death rate is constant throughout the range. On this assumption we calculated, for infants in each age range and dying in each quarter of the year, the proportion born in that quarter and in preceding quarters. These proportions were then used as a basis for calculating the cohort of live births from which those dying were drawn. To show the trend over the years, we calculated a seven-point moving average, weighting the data with binomial coefficients (that is, $1,6,15,20,15,6,1$ ). Such weighting seems preferable to a straightforward moving average because it gives greater weight to the years closer in time to the year for which the average is calculated.

Any study of the correlation between infant death rates and temperature over a considerable period of years is complicated by the general downward trend in death rates since 1911. Two methods of avoiding this difficulty derive from the use of a yearly index which is not directly dependent on the level of the death rates. One index is the ratio of the rate in a particular year to the rate averaged over a number of years immediately preceding and succeeding that year. This index, which we here call the first index, may refer to the rate in a particular quarter or to a yearly rate. We have used an average rate based on the 9 years centred on the year in question. The use of 9 years is somewhat arbitrary, but there were very similar results when the number was 5,7 or 11 . The other index, our second index, is the ratio of the rate in one quarter of the year to the rate for the year as a whole. These two indices depend on somewhat different aspects of the same data, and in so far as their use leads to the same results, we think this increases the trust which can be placed in our procedures and conclusions.

As a measure of the degree of seasonal variation occurring in any particular year, we used the ratio of the rate in the first quarter of the year to that in the third quarter. This seems reasonable because, with very few exceptions, the seasonal rate was highest in the first quarter and lowest in the third quarter of the year.

\section{Results}

Findings for the age groups of under one week and of 1-3 weeks were very similar; and the three groups 3-5 months, 6-8 months, and 9-11 months were also very similar to one another. The presentation can therefore be simplified, and Figs. 1-4 show the trends of the quarterly rates for stillbirths and for deaths in the three age groups (a) less than four weeks, (b) 1-2 months, (c) 3-11 months. Fig. 5 shows, for each of

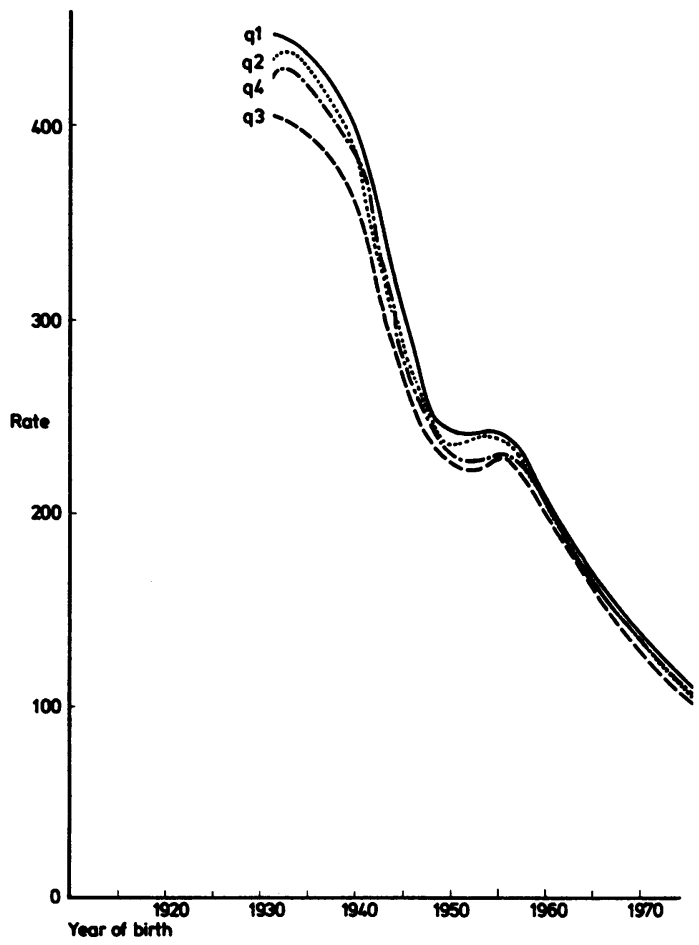

Fig. 1 Stillbirth rates, by quarter (q) of the year, England and Wales. Rates per $10^{4}$ live births. Curves based on 7-year moving average of rates for the years 1928-78. 


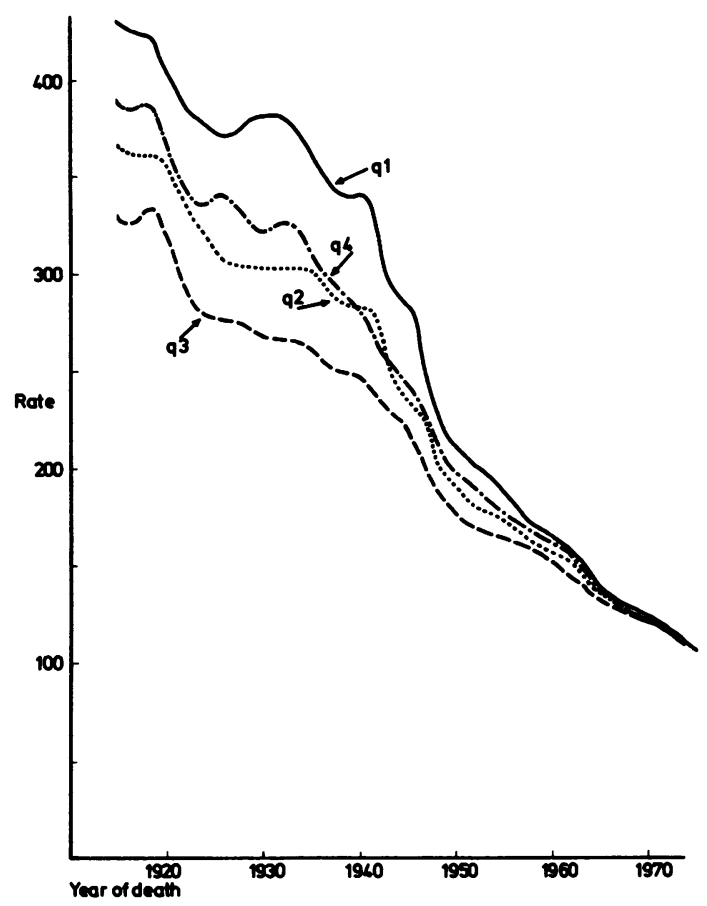

Fig. 2 Neonatal death rates, by quarter of the year, England and Wales. Rates per $10^{4}$ cohort births. Curves based on 7-year moving average of rates for the years. 1912-78.

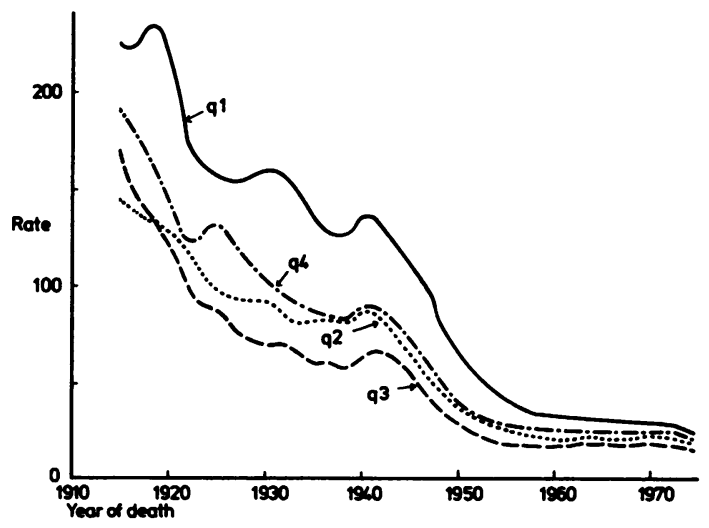

Fig. 3 Death rates, by quarter of the year, for deaths at 1-2 months of age, England and Wales. Rates per $10^{4}$ cohort births. Curves based on 7-year moving average of rates for the years 1912-78.

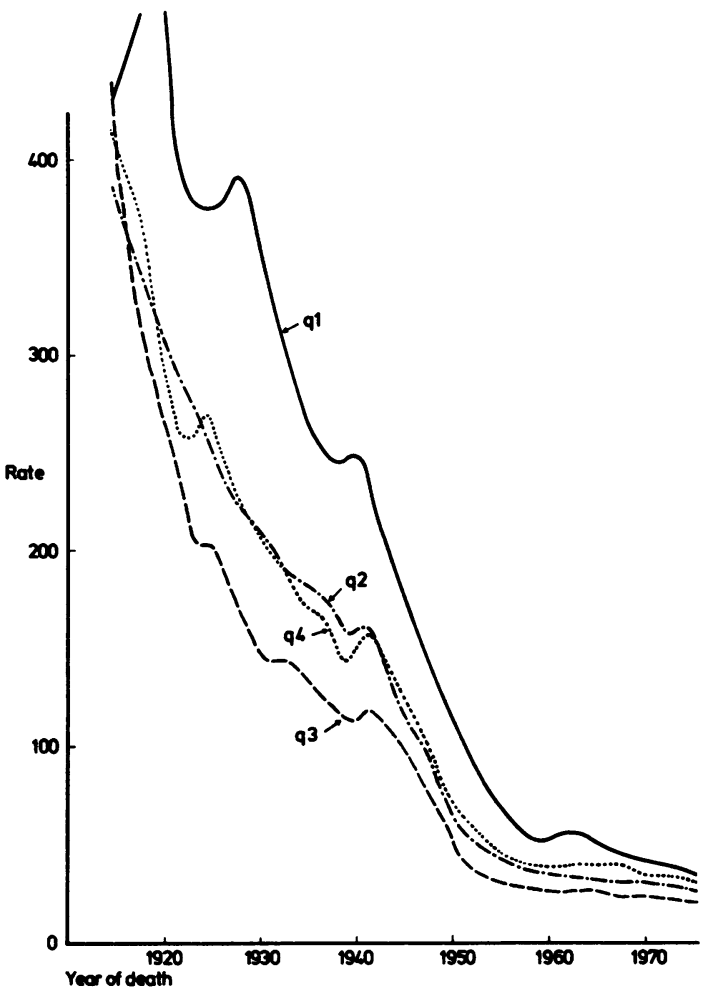

Fig. 4 Death rates, by quarter of the year, for deaths at 3-11 months of age, England and Wales. Rates per 104 cohort births. Curves based on 7-year moving average of rates for the years 1912-78.

the various age groups, the changes in the index of seasonal variation. For stillbirths, seasonality has never been marked since the quarterly numbers were first recorded, but by about 1950 the seasonal rates became almost equal and have remained so since then, though with the suggestion of a recent trend to seasonality again. For deaths under four weeks of age, seasonal difference in rates largely disappeared by about 1965 . The two older age groups have not shown deseasonality, though for deaths at 1-2 months there is a trend towards this.

The correlation coefficients between the mean Q1 temperature and the two indices used to represent the $Q 1$ death rate are shown in Tables 1 and 2. The same general trends are shown for both indices. Correlations tended to be highest during the years up to 1940 (the interwar period). For stillbirths, and to a lesser degree for neonatal deaths, the correlations fell sharply thereafter. But for the two oldest groups, and for all ages under one year, the fall was much less. 
Table 1 Correlation coefficients between temperatures and rates during the first quarter of the year, using the first index of rates, that is, ratio of rate in a particular quarter to the 9-year average rate

\begin{tabular}{|c|c|c|c|c|c|}
\hline Period & $\begin{array}{l}\text { Stillbirth } \\
\text { rate }\end{array}$ & $\begin{array}{l}\text { Death rates } \\
\text { Under } \\
4 \text { weeks }\end{array}$ & $\begin{array}{l}\text { for deaths a } \\
1-2 \\
\text { months }\end{array}$ & $\begin{array}{l}\text { 3-11 } \\
\text { months }\end{array}$ & $\begin{array}{l}\text { Under } \\
\text { I year }\end{array}$ \\
\hline $\begin{array}{l}1921-40 \dagger \\
1941-60 \\
1961-74\end{array}$ & $\begin{array}{l}-0.71^{*} \\
-0.38 \\
+0.14\end{array}$ & $\begin{array}{l}-0.85 * \cdots \\
-0.75 \cdots \cdots \\
-0.18\end{array}$ & $\begin{array}{l}-0.56^{\circ} \\
-0.49^{\circ} \\
-0.46\end{array}$ & $\begin{array}{l}-0.70^{*} * \\
-0.47^{*} \\
-0.57^{*}\end{array}$ & $\begin{array}{l}-0.77^{* * *} \\
-0.66^{* *} \\
-0.49\end{array}$ \\
\hline
\end{tabular}

$\$ 1932-40$ for stillbirths.

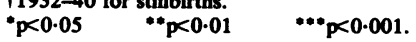

Table 2 Correlation coefficients between temperatures and rates during the first quarter of the year, using the second index of rates, that is, ratio of the first quarter rate to the annual rate in the same year

\begin{tabular}{|c|c|c|c|c|c|}
\hline Period & $\begin{array}{l}\text { Stillbirth } \\
\text { rate }\end{array}$ & $\begin{array}{l}\text { Death rates } \\
\text { Under } \\
4 \text { weeks }\end{array}$ & $\begin{array}{l}\text { for death } \\
1-2 \\
\text { months }\end{array}$ & $\begin{array}{l}3-11 \\
\text { months }\end{array}$ & $\begin{array}{l}\text { Under } \\
1 \text { year }\end{array}$ \\
\hline $\begin{array}{l}1921-40 \dagger \\
1941-60 \\
1961-78\end{array}$ & $\begin{array}{l}-0.50 \\
-0.25 \\
-0.05\end{array}$ & $\begin{array}{l}-0.78^{*} \\
-0.55^{\circ} \\
-0.23\end{array}$ & $\begin{array}{l}-0.33 \\
-0.24 \\
-0.31\end{array}$ & $\begin{array}{l}-0.58 \\
-0.23 \\
-0.43\end{array}$ & $\begin{array}{l}-0.67^{\circ} \\
-0.37 \\
-0.47^{\circ}\end{array}$ \\
\hline
\end{tabular}

$\uparrow 1928-40$ for stillbirths.

$* p<0.05 \quad * p<0.01 \quad * * p<0.001$.
The matrix of correlations between temperatures and death rates for various quarters of the year and for the period 1921-60 are shown in Table 3, where the following points may be noted. (1) It is the Q1 temperature which is most closely related to death rates, for in each age group this temperature shows a high negative correlation with the rates for $\mathrm{Q1}, \mathrm{Q} 2$, the first half of the year, and the year as a whole. (2) For each age group, the mean temperature of the first half of the year correlates highly with the rates for this half-year and for Q2. (3) Temperatures of Q2 showed no significant correlation with any rates. Temperature and rates for Q4 are not shown in the Table, but with a single exception-which may properly be attributed to chance-there were no significant correlations between $\mathrm{Q} 4$ temperatures and any seasonal rate, or between Q4 rates and any seasonal temperature. (4) For deaths at 1-2 months and 3-11 months there is a significant correlation between rates in $Q 1$ and the temperature of the preceding quarter. (5) For deaths at 3-11 months and for all deaths under one year, there are significant positive correlations between temperature and rates in Q3.

Correlation coefficients between the rate in a particular year and the degree of seasonal variation in that year, as measured by the ratio of Q1 to Q3 rates, are shown in Table 4. These are all positive, and that for neonatal deaths is notably high.

Table 3 Correlation coefficients between seasonal temperatures and infant death rates for 1921-60 (using the first index of rates, that is, ratio of rate in a particular quarter to the 9-year average rate)

\begin{tabular}{|c|c|c|c|c|c|c|}
\hline \multirow[b]{2}{*}{ Death rate } & \multicolumn{6}{|c|}{ MEAN TEMPERATURE OF: } \\
\hline & $\begin{array}{l}\text { Previous } \\
\text { 4th quarter }\end{array}$ & Ist quarter & 2nd quarter & 1st half-year & 3rd quarter & Year \\
\hline $\begin{array}{l}\text { FOR DEATHS UNDER } 4 \text { WEEKS } \\
\text { During 1st quarter } \\
\text { 2nd quarter } \\
\text { 1st half-year } \\
\text { 3rd quarter } \\
\text { Year }\end{array}$ & $\begin{array}{l}-0.14 \\
+0.03 \\
-0.09 \\
+0.05 \\
-0.07\end{array}$ & $\begin{array}{l}-0.75 \\
-0.58 \\
-0.76 \\
-0.06 \\
-0.59\end{array}$ & $\begin{array}{l}+0.03 \\
-0.17 \\
-0.06 \\
+0.16 \\
-0.07\end{array}$ & $\begin{array}{l}-0.44 \\
-0.58 \\
-0.68 \\
+0.04 \\
-0.47\end{array}$ & $\begin{array}{l}+0.04 \\
+0.00 \\
+0.03 \\
+0.24 \\
+0.12\end{array}$ & $\begin{array}{l}-0.38 \\
-0.30 \\
-0.38 \\
+0.17 \\
-0.24\end{array}$ \\
\hline $\begin{array}{l}\text { FOR DEATHS AT 1-2 MONTHS } \\
\text { During 1st quarter } \\
\text { 2nd quarter } \\
\text { 1st half-year } \\
\text { 3rd quarter } \\
\text { Year }\end{array}$ & $\begin{array}{l}-0.34 \\
+0.12 \\
-0.16 \\
-0.08 \\
-0.11\end{array}$ & $\begin{array}{l}-0.52 \\
-0.37 \\
-0.55 \\
+0.02 \\
-0.35\end{array}$ & $\begin{array}{l}-0.12 \\
-0.21 \\
-0.18 \\
+0.11 \\
-0.01\end{array}$ & $\begin{array}{l}-0.50 \\
-0.42 \\
-0.55 \\
+0.08 \\
-0.30\end{array}$ & $\begin{array}{l}+0.11 \\
-0.11 \\
+0.04 \\
+0.26 \\
+0.12\end{array}$ & $\begin{array}{l}-0.24 \\
-0.41 \\
-0.37 \\
+0.18 \\
-0.17\end{array}$ \\
\hline $\begin{array}{l}\text { FOR DEATHS AT 3-11 MONTHS } \\
\text { During 1st quarter } \\
\text { 2nd quarter } \\
\text { 1st half-year } \\
\text { 3rd quarter } \\
\text { Year }\end{array}$ & $\begin{array}{l}-0.34 \\
-0.02 \\
-0.27 \\
-0.06 \\
-0.25\end{array}$ & $\begin{array}{l}-0.53 \\
-0.53 \\
-0.62 \\
+0.06 \\
-0.48\end{array}$ & $\begin{array}{l}-0.12 \\
-0.17 \\
-0.16 \\
+0.10 \\
-0.05\end{array}$ & $\begin{array}{l}-0.51 \\
-0.54 \\
-0.61 \\
+0.11 \\
-0.43\end{array}$ & $\begin{array}{l}+0.04 \\
+0.05 \\
+0.05 \\
+0.51 \\
+0.17\end{array}$ & $\begin{array}{l}-0.29 \\
-0.38 \\
-0.38 \\
+0.33 \\
-0.21\end{array}$ \\
\hline $\begin{array}{l}\text { FOR DEATHS UNDER } 1 \text { YEAR } \\
\text { During 1st quarter } \\
\text { 2nd quarter } \\
\text { 1st half-year } \\
\text { 3rd quarter } \\
\text { Year }\end{array}$ & $\begin{array}{l}-0.28 \\
+0.05 \\
-0.19 \\
-0.01 \\
-0.14\end{array}$ & $\begin{array}{l}-0.66 \\
-0.59 \\
-0.72 \\
+0.03 \\
-0.57\end{array}$ & $\begin{array}{l}-0.09 \\
-0.24 \\
-0.16 \\
+0.15 \\
-0.01\end{array}$ & $\begin{array}{l}-0.61 \\
-0.62 \\
-0.70 \\
+0.11 \\
-0.49\end{array}$ & $\begin{array}{l}+0.02 \\
-0.03 \\
+0.01 \\
+0.45 \\
+0.15\end{array}$ & $\begin{array}{l}-0.36 \\
-0.45 \\
-0.44 \\
+0.32 \\
-0.25\end{array}$ \\
\hline
\end{tabular}

$p=0.05,0.01$, and $0.001(38 \mathrm{df}$ when $\tau=0.32,0.41$, and 0.50 respectively.

Bold type denotes coefficients significant at the $1 \%$ level. 


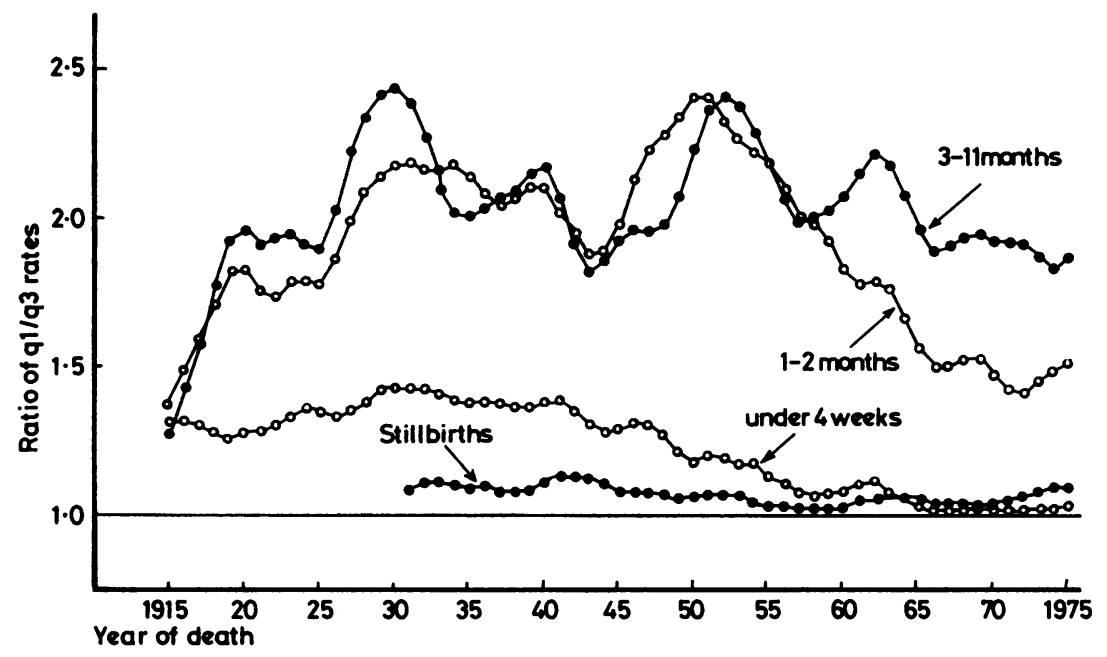

Fig. 5 Seasonality of rates (measured as the ratio of first quarter rate to third quarter rate) for stillbirths and for deaths at three age groups. Curves based on 7-year moving average of rates: stillbirths 1928-78, deaths 1912-78.

\section{Discussion}

Sakamoto-Momiyama* showed that deseasonality of death rates, both for total and for infant mortality, had occurred in the United States of America, Canada, Norway, and Sweden by the 1920s; and that the Netherlands, Germany, and Switzerland were showing trends towards this by the 1960 s, a time when Japan, the United Kingdom, and Italy still showed marked seasonality with high winter rates. But she observed, using data up to 1965 , that England seemed "likely to show signs of deseasonalisation before long' ( $p$ 50). The present results show that deseasonality has occurred in England and Wales for the stillbirth rate and for neonatal death rate; the trend is that way for deaths at 1-2 months, but there is no clear trend in deaths at 3-11 months. A similar relation between age at death and the degree of seasonal variation in death rate is apparent in Japanese figures for infant deaths from pneumonia and bronchitis during the years 1969-72 (Sakamoto-Momiyama4 p 152, Fig. 7.9).

Sakamoto-Momiyama suggested that the decrease and disappearance of high winter death rates was related to the introduction of central heating, for deseasonality occurred earliest in countries with very cold winters where central heating would be used as soon as available, while in the other countries with milder winters, central heating would be introduced more gradually. Because, on the present findings, deseasonality has occurred for neonatal but not for postneonatal death rates, we should need, on
Sakamoto-Momiyama's hypothesis, to suppose that it is younger rather than older infants who have been affected by the introduction of central heating - a not unreasonable supposition, as younger infants are more likely to be kept indoors during cold weather. On the other hand, it is the older age groups which show the greatest seasonal variation in mortality, and which have shown the greatest relative fall in mortality over the past 60 years-circumstances which suggest that even a moderate benefit from central heating might have been expected to show some deseasonalising effect. The failure to demonstrate a trend towards deseasonality in these older infants in the present study, and the low negative correlation between their annual rate and seasonal variation, in contrast to the high positive correlation found for deaths under the age of four weeks, support the conclusion of Macfarlane $^{b}$ that the postneonatal mortality rate is

Table 4 Correlation coefficients between yearly ratest of stillbirths and infant deaths and the seasonal variation in these rates (seasonal variation measured as the ratio of rates in the first and third quarters of the year)

\begin{tabular}{ll}
\hline Rotes & Correlation coefficient \\
\hline Stillbirths & $0.34^{* *}$ \\
Infant deaths at: & $0.91^{* \cdots *}$ \\
Under 4 weeks & 0.25 \\
$1-2$ months & 0.06 \\
$3-11$ months & $0.74^{\cdots \cdots}$ \\
\hline Under 1 year & \\
\hline
\end{tabular}

†1928-78 for stillbirths; 1921-78 for infant deaths. -p<0.01 $\cdots p<0.001$. 
not directly associated with its seasonal variation. These findings also support the view ${ }^{7}$ that there is a considerable difference in the factors determining perinatal and postneonatal mortality.

Our finding of a correlation between infant death rates and environmental temperature confirms and perhaps extends previous work on the subject. ${ }^{1-3} \mathrm{This}$ relation is only a particular instance of a general relation between mortality rates and temperature..$^{8-10}$ Bull and Morton ${ }^{11}$ showed, for monthly deaths in England and Wales during 1963-66, (a) that there was a close association between death rate and temperature for most diseases other than carcinoma, and that this association was much stronger in the elderly than in younger subjects; (b) that the death rate might be associated with temperatures occurring three weeks or more before the date of death; and (c) that whereas colder temperatures were associated with higher death rates, high rates were also associated with periods of particularly high temperature. Our present findings may be considered in line with those of Bull and Morton. It would not be unexpected that the increased susceptibility to external temperature shown by the very old should also be shown by the very young. We find a strong association between temperature and infant death rates, even where these indices are averaged over periods of three months and more (and it may be noted that the period January-March is not necessarily the best measure of the cold season, though we had to use this period because numbers of births by month of birth have been published only since 1939). And we find, for deaths in older infants, a positive correlation between rate and temperature in the third (summer) quarter of the year (Table 3).

The relation between temperatures and rates in the first and third quarters of the year probably accounts for the peaks in the graph of $Q 1 / Q 3$ ratios for deaths at 3-11 months (Fig. 5); these peaks are related to years with particularly cold winters. The peaks are reflected to a lesser degree for deaths at earlier ages.

A general point may be made about secular changes in early death rates. By about 1920 , the previously common summer excess in death rates, related to summer diarrhoea, had practically disappeared, and summer rates became the lowest of the seasonal rates; and by 1950, the high winter death rates began to diminish for deaths under the age of three months. The present findings give emphasis to Boyd' ${ }^{3}$ suggestion that the low correlations found by Young $^{1}$ - and the even lower ones by Woods ${ }^{12}$ - over a period of 50 years and more' from the middle of the last century were the consequence of changing patterns of seasonal mortality, while the high correlations found by Wright and Wright for the interwar years, similar to those found in the present study for the same period, more truly reflect the high dependence of death rate on temperature during that particular time. Such secular changes imply that a correlation between seasonal mortality and any particular environmental factor is not likely to remain constant, or to be susceptible of a single interpretation, when taken over a considerable period of years; and that even over short periods, attention needs to be given to the continually changing nature, seasonal or otherwise, of the patterns of mortality.

We thank the Director General of the Meteorological Office, Bracknell, Berkshire, for supplying the meteorological data.

Reprints from Dr. E. H. Hare, the Maudsley Hospital, Denmark Hill, London SE5 8AZ.

\section{References}

${ }^{1}$ Young M. The influence of weather conditions on the mortality from bronchitis and pneumonia in children. $J$ Hyg (Camb) 1924; 23: 151-75.

2 Wright GP, Wright HP. Etiological factors in broncho-pneumonia amongst infants in London. $\mathrm{J} \mathrm{Hyg}$ (Camb) 1945; 44: 15-30.

'Boyd JJ. Climate, air pollution and mortality. Br J Prev Soc Med 1960; 14: 123-35.

4Sakamoto-Momiyama M. Seasonality in Human Mortality. Tokyo: University of Tokyo Press, 1977.

' Registrar General. Annual Statistical Report for the Year 1922. Text, Medical, Table V. London: HMSO, 1923: 12.

- Macfarlane A. Seasonal variation in post-neonatal mortality. Studies in Medical and Population Subjects 1981 (in press).

'Office of Population Censuses and Surveys. Infant and Perinatal Mortality 1976. OPCS Monitor, DH1, 77/1, 19 January 1977. London: HMSO, 1977.

- Bainton D, Moore F, Sweetnam P. Temperature and deaths from ischaemic heart disease. Br J Prev Soc Med 1977; 31: 49-53.

- Macfarlane A. Daily mortality and environment in English conurbations. I: Air pollution, low temperature, and influenza in Greater London. Br J Prev Soc Med 1977; 31: 54-61.

${ }^{10}$ Macfarlane A. Daily mortality and environment in English conurbations. II: Deaths during summer hot spells in Greater London. Environ Res 1978; 15: 332-41.

"Bull GM, Morton J. Environment, temperature and death rates. Age Ageing 1978; 7: 210-22.

${ }^{12}$ Woods HM. The influence of external factors on the mortality from bronchitis and pneumonia in children. $J$ Hyg (Camb) 1926; 26: 36-43. 